\title{
Genetic analysis in Finnish families with inflammatory bowel disease supports linkage to chromosome 3p21
}

\author{
Paulina Paavola ${ }^{1}$, Tiina Heliö ${ }^{1}$, Maija Kiuru ${ }^{1}$, Leena Halme ${ }^{2}$, Ulla Turunen ${ }^{1}$, \\ Joseph Terwilliger ${ }^{3}$, Anna-Liisa Karvonen ${ }^{4}$, Risto Julkunen ${ }^{5}$, Seppo Niemelä ${ }^{6}$, \\ Heimo Nurmi ${ }^{7}$, Martti Färkkilä ${ }^{1}$ and Kimmo Kontula ${ }^{*, 1}$
}

\author{
${ }^{1}$ Department of Medicine, Helsinki University Hospital, Helsinki, Finland; ${ }^{2}$ Department of Surgery, Helsinki \\ University Hospital, Helsinki, Finland; ${ }^{3}$ Columbia University, New York, USA; ${ }^{4}$ Department of Medicine, Tampere \\ University Hospital, Tampere, Finland; ${ }^{5}$ Department of Medicine, Kuopio University Hospital, Kuopio, Finland; \\ ${ }^{6}$ Department of Gastroenterology, Oulu University Hospital, Oulu, Finland; ${ }^{7}$ Department of Medicine, Turku \\ University Hospital, Turku, Finland
}

In inflammatory bowel diseases (IBD), certain chromosomal candidate loci have been repeatedly identified by independent studies in different populations. To investigate the contribution of the loci on chromosomes 1,3 , $7,12,14$, and 16 to the susceptibility of IBD in Finnish population, where the predominant feature is the excess of ulcerative colitis (UC) families compared to Crohn's disease (CD) families, we carried out linkage analyses using 93 Finnish, multiply-affected IBD families. We observed nominal evidence for linkage to chromosome 3 p21, consistent with earlier reports. The lod scores peaked at D3S2432, with a maximum two-point lod score of 1.68 ( $P=0.0027)$. In addition, we studied whether risk of IBD is associated with functional variants of two positional candidate genes; the chemokine receptor CCR5 gene on chromosome $3 p 21$ and the interleukin-4 receptor $\alpha$-subunit gene (IL4RA) on chromosome 16. We did not find any significant correlation between a 32 bp deletion variant of CCR5 or a single nucleotide change A1902G (GIn576Arg) of IL4RA, and IBD phenotypes, with the exception that in the UC group homozygosity for the $\mathrm{G} 1902$ allele of IL4RA was less frequent (0.019 vs $0.049, P=0.038$ ). In conclusion, our study, carried out in a genetically homogenous population, suggests that chromosome 3 may contain a susceptibility gene for IBD. European Journal of Human Genetics (2001) 9, 328 - 334.

Keywords: chromosome mapping; genetic predisposition to disease; inflammatory bowel diseases; linkage; lod score; microsatellite repeats

\section{Introduction}

Studies of the genetic susceptibility to inflammatory bowel disease (IBD) have resulted in the discovery of several chromosomal areas of interest during recent years. The most encouraging results concern Crohn's disease (CD) which is linked in most studied populations to chromosome 16 pericentromeric region (IBD1 locus), ${ }^{1-10}$ and in

*Correspondence: Dr Kimmo Kontula, Professor of Molecular Medicine, Department of Medicine, University of Helsinki, Haartmaninkatu 4, PL 340, 00290 Helsinki, Finland.

Tel: +358 94717 2230; Fax: +358 94717 4013;

E-mail: Kimmo.Kontula@hus.fi

Received 5 September 2000; revised 6 December 2000; accepted 18 December 2000 two independent studies to chromosome $14 .^{11,12}$ Evidence for a relatively strong genetic basis of $\mathrm{CD}$ has also earlier been obtained by epidemiological data. For instance, the reported concordance rate of the disease between monozygotic twins is greater for CD $(20-44 \%)$ than ulcerative colitis (UC, 6-16\%). ${ }^{13}$ Linkage to another promising IBD locus (IBD2) on chromosome 12 has been supported by many independent studies, especially in UC families. $^{2,7,10,11,14}$ The locus on chromosome $6 \mathrm{p}$ referred to as IBD3 locus is not as definitively replicated as the IBD1 and IBD2 loci. ${ }^{15-17}$ Linkage to chromosome 1 in American Chaldean population is the only linkage report, so far, from an isolated population, ${ }^{18}$ that strengthens and restricts the assignment of the susceptibility locus previously reported in outbred population. ${ }^{6}$ 
The Finnish population represents a genetic isolate and may provide advantages in genetic studies on complex diseases. Based on epidemiological data from the southcentral part of the country, the prevalence of UC has been estimated as 121/100 000 and that of CD as 44/100 000 among the Finns. ${ }^{19}$ As the first part of a systematic search for IBD susceptibility genes in the Finnish population, we conducted a linkage study on the most attractive candidate loci on chromosomes 1, 3, 7, 12, 14 and 16 in 93 IBD families. In addition, functional alterations in two positional candidate genes, ${ }^{20-22}$ one encoding the chemokine receptor CCR5 on chromosome 3p21 and the other encoding the interleukin-4 receptor alpha subunit (IL4RA) on chromosome 16, were analysed in a separate case-control study of unrelated individuals.

\section{Materials and methods}

\section{Family ascertainment and sample collection}

We recruited IBD patients from all over Finland using strict diagnostic criteria based on typical clinical characteristics as well as diagnostic findings on both visual inspection by successful ileocolonoscopy and histopathological examination of biopsy specimens. The clinical diagnosis of each patient was confirmed by at least two members of the research group. Individual families consisting of at least two siblings with a diagnosis of either CD, UC or indeterminate colitis, were identified and collected. Families with a history of IBD in the relatives of both parents of the sib-pairs were excluded. Eventually 93 IBD families, containing a total of 124 sib-pairs, were accepted into the linkage study (Table 1). Both parents were available for analysis in 38\% of the 93 families. The definition for a mixed family denotes sibships with both UC and CD; only in five families one of the siblings had indeterminate colitis. In the association study, we genotyped 155 familial (with a known 1st degree affected relative) IBD patients, 280 sporadic IBD patients, and 183 healthy controls for the common CCR5 and IL4RA polymorphisms. The controls were healthy voluntary blood

Table 1 Structure of the family cohort

\begin{tabular}{lrccc}
\hline Sibship size & UC & Mixed & $C D$ & All \\
\hline 2 & 35 & 13 & 15 & 63 \\
3 & 5 & 3 & & 8 \\
4 & 1 & 1 & & 2 \\
$2+3^{\text {a }}$ & 6 & 1 & 1 & 1 \\
$2+$ ARP & 3 & 5 & & 3 \\
3+ARP & 3 & 1 & & 4 \\
ARPs only & & & 16 & 93 \\
Total families & 53 & 24 & 16 & 124 \\
Total sib-pairs & 71 & 37 & &
\end{tabular}

${ }^{\mathrm{a}}$ Two and three sibs in successive generations.

${ }^{\mathrm{b}}$ ARP denotes for affected pair; uncle or aunt/niece or nephew pair, grandparent/grandchild pair, half-sibling pair, or cousin pair. donors (91 men, 92 women) aged 40 to 50 years (mean 45 years) collected from the Finnish Red Cross Blood Service, and had their residencies in the capital region of Finland where approximately $70 \%$ of the patients were living. In addition, we genotyped the whole family cohort (Table 1) for the IL4RA polymorphism. Informed written consent was obtained from all study participants, and the study protocol was accepted by the Ethical Review Committee of Helsinki University Central Hospital.

\section{Genetic analysis}

All the blood samples for DNA isolation were collected in accordance with the Helsinki declaration. Microsatellite markers spanning the IBD candidate regions originated from the marker collections of Généthon and the Cooperative Human Linkage Center (CHLC) (http://lpg.nci.nih.gov/ CHLC/). Genotyping was performed using 96-well format both in PCR with fluorescently labelled primers and in electrophoresis of the pooled amplified products. Data collection was based on the use of an ABI377 automated DNA sequencer (Perkin Elmer, Applied Biosystems), and data analyses were performed with the Genescan 2.0 and Genotyper software programs. The genotype data were processed using LINKBASE, the Windows-based database system designed to connect the genotype data produced by automatic sequencers to linkage analysis programs (http:// www.ktl.fi/molbio/software/linkbase).

\section{Analyses of candidate gene polymorphisms}

Genotyping of the CCR5 insertion/deletion polymorphism was performed by amplifying DNA by PCR using primers $5^{\prime}$ T G T T T G C G T C T C T C C C A G - $3^{\prime}$ and $5^{\prime}$ - C A CAGCCCTGTGCCTCTT-3' resulting in a $232 \mathrm{bp}$ product for the wild type allele and a $200 \mathrm{bp}$ product for the mutant allele $(\Delta 32)$ upon agarose gel electrophoresis. The A1902G polymorphism of the IL $4 R A$ gene was genotyped according to the protocol described by Noguchi et al. ${ }^{23}$

\section{Statistical analysis}

In order to take advantage of the extended nature of the family cohort, two-point pairwise linkage analyses using affecteds-only dominant and recessive pseudomarker analysis were performed, ${ }^{24}$ using the MLINK program of the LINKAGE package, ${ }^{25}$ FASTLINK version $2.2 .^{26}$ This method is analogous to comparison of the proportion of alleles affected relatives share identical by descent in families of general structure. ${ }^{24} \mathrm{~A}$ two-point analysis was preferred to multipoint analysis because the latter is more sensitive to misspecification of intermarker distances and allele frequencies. ${ }^{24} P$ values $<0.05$ are presented in the tables, to allow the comparison of lod scores and non-parametric lod (NPL) scores that were used in most of the previous IBD reports. We also present for each marker the NPL scores calculated by using the Genehunter 2.0 beta software. ${ }^{27}$ Multipoint NPL analyses for each chromosome were also performed but they 
did not significantly add information content on the families that we studied. The identity-by-descent status in the affected sib-pairs was analysed by the SIBPAIR program. Linkage disequilibrium was tested with a haplotype relative risk test (HRR-test) and genetic heterogeneity using HOMOG, as incorporated in the ANALYZE package. ${ }^{28}$ For each marker, the allele frequencies were estimated from the total study sample.

Power analyses were performed to estimate the probability of detecting linkage under various gene effect sizes, eg, proportion of linked families $(\alpha)$, using the SIMSIBS program which was also used for the simulation analyses in the articles by Terwilliger et al. and Göring et al. ${ }^{24,29}$ The extended nature of our family cohort was not taken into account, but the estimates were based on the total amount of sib-pairs of our family cohort. On the other hand, these power calculations assume that genotypes were known for all individuals. We assumed the average marker heterozygosity to be $80 \%$ and recombination fraction of 0.05 between marker and disease loci. Based on the calculations, under this sample size (only sibships included) our family cohort could permit detection of major loci $(\alpha>0.40)$ contributing to susceptibility to IBD (data not shown). The statistical analysis for association in the candidate gene study was performed by using Pearson chi-square statistics with the BMDP software (BMDP Statistical Software Inc., Los Angeles, CA, USA).

\section{Results}

\section{Linkage analyses of candidate chromosomal loci}

The family cohort consisted of 53 UC families, $16 \mathrm{CD}$ families, and 24 mixed families, containing 229 affected individuals (114 male and 115 female) and 145 non-affected individuals. The majority of the patients $(68.4 \%)$ had diagnosis of UC $(n=156)$. Five patients had the diagnosis of indeterminate colitis and 68 patients the diagnosis of CD. The age of the patients ranged from 12 to 86 years (mean and median, 47 years). The mean age of disease onset (age at diagnosis) was slightly lower in CD families (mean 28.4 years, median 27.5 years) compared to UC families (mean 33 years, median 30 years) or mixed families (mean 33 years, median 32.5 years).

Nominal evidence for linkage was observed on chromosome 3p21. The lod scores peaked at D3S2432 where the maximum two-point lod score obtained by the recessive pseudomarker analysis was $1.68(P=0.0027, \theta=0.26)$ and the NPL score $1.89(P=0.029)$ (Table 2$)$. In the multipoint NPL analysis the maximum lod score was $1.71(P=0.043)$ near D3S2432. As the family composition did not represent a pure sib-pair material, the lod score in affected sib-pair analysis (ASP) for the total study sample (lod score $=1.48 ; P=0.0045$ ) was slightly less significant. The marker D3S1619, approximately $3 \mathrm{cM}$ telomeric to D3S2432, gave a maximum lod score of $0.98(P=0.017)$ in the recessive pseudomarker linkage analysis. Stronger evidence for linkage was obtained in the mixed group where the lod score was $1.47(P=0.0047$, Table $3)$. In the UC group at D3S1619, the haplotype relative risk test gave a $P$-value of 0.019 (0.057 for the total family cohort and 0.03 for the UC-mixed group), which reflects a minor overrepresentation of the allele 9 in the affected chromosomes (23\%) compared to control chromosomes (10\%).

The analyses carried out for subgroups defined by disease onset (age $<30$ or $<22$ years) or parents' birth places (Southwestern vs Northeastern Finland) did not give any more significance to the linkage analysis (data not shown). Multipoint non-parametric analyses did not add information content on the families that we studied: for $3 \mathrm{p} 21$ the highest two-point NPL score was 1.89 whereas the highest multipoint NPL score was 1.71 near D3S2432. In the disease-specific analyses, CD families did not seem to contribute to the linkage evidence (Table 3), which was also evident in the multipoint NPL analyses on 3p21 (Figure 1). On chromosome 16 , in the affecteds-only analysis the marker D16S407 gave a maximum two-point lod score of $0.93(P=0.019)$ and a NPL score of $1.63(P=0.049)$ for the $C D$ group consisting of 16 families with two affected sibs (Table 2). Here also, the multipoint NPL analysis did not give any more significance to the results (data not shown). In other groups, and in the total study group, the lod scores for chromosome 16 markers remained non-significant. The non-significant results for other loci on chromosomes 1, 7, 12 and 14 are presented in Table 2.

\section{Association analyses of the functional variants of CCR5 and IL4RA}

The genotype or allele frequencies of the CCR5 insertion/ deletion polymorphism did not differ significantly between the unrelated inflammatory bowel disease (IBD) patients and controls (Table 4). Furthermore, no significant differences in these frequencies emerged, when calculations were carried out in different disease types, or when sporadic IBD was compared to familial IBD. The IL4RA allele (A1902G) frequencies were similar in the IBD group and the control group, but the genotype frequencies showed minor differences in these two groups (Table 4). There was no significant deviation of the observed genotype frequencies from the Hardy-Weinberg's equilibrium in the patient or control groups $(P>0.10)$. In the IBD group, the homozygous genotype for the variant allele $1902 \mathrm{G}$ was less frequent $(0.019$ vs $0.049, P=0.038)$ and the heterozygous genotype more frequent $(0.36$ vs 0.28$)$ than the corresponding frequencies in the controls. No excess transmission of either of the IL4RA alleles to affected individuals was observed in the HRR-test of the whole family cohort $(P=0.33)$.

\section{Discussion}

The present study supports the assumption that one of the genes conferring increased risk of IBD is located on 
Table 2 Two-point linkage analysis of the candidate IBD loci

\begin{tabular}{|c|c|c|c|c|c|c|}
\hline Chr & Marker & $c M$ & \multicolumn{3}{|c|}{$Z_{\max }$} & NPL score \\
\hline 1 & D1S552 & 45.3 & 0.52 & $0.90(0.021)$ & 0.31 & 1.09 \\
\hline \multirow[t]{6}{*}{$3 p$} & D3S2396 & 46.5 & 0.07 & 0.00 & 0.03 & 0.02 \\
\hline & D3S1609 & 49.5 & 0.10 & 0.20 & 0.30 & 0.32 \\
\hline & D3S2432 & 51.0 & $1.68(0.0027)$ & $1.12(0.012)$ & $1.48(0.0045)$ & $1.89(0.029)$ \\
\hline & D3S2304 & 63.0 & 0.02 & 0.13 & 0.05 & 0.16 \\
\hline & D3S1573 & 67.0 & 0.23 & 0.25 & 0.06 & 0.51 \\
\hline & D3S1766 & 74.0 & 0.15 & 0.25 & 0.02 & 0.41 \\
\hline \multirow{2}{*}{$3 q$} & D3S3053 & 195.0 & 0.04 & 0.23 & 0.007 & 0.70 \\
\hline & D3S2427 & 207.0 & $0.75(0.031)$ & 0.57 & $0.64(0.043)$ & 1.40 \\
\hline \multirow[t]{2}{*}{7} & D7S484 & 55.6 & 0.07 & 0.24 & 0.00 & 0.58 \\
\hline & D7S519 & 70.0 & 0.12 & 0.008 & 0.05 & -0.23 \\
\hline \multirow{5}{*}{12} & D12S1662 & 76.4 & 0.0004 & 0.00 & 0.00 & 0.09 \\
\hline & $\mathrm{D} 12 \mathrm{~S} 83$ & 76.5 & 0.00 & 0.01 & 0.00 & -0.25 \\
\hline & D12S1655 & 76.6 & 0.00 & 0.00 & 0.00 & -0.45 \\
\hline & $\mathrm{D} 12 \mathrm{~S} 43$ & 86.0 & 0.00 & 0.00 & 0.002 & -0.20 \\
\hline & D12S95 & 98.0 & 0.01 & 0.00 & 0.00 & 0.16 \\
\hline 14 & D14S261 & 6.5 & 0.02 & 0.00 & 0.00 & -0.42 \\
\hline \multirow{8}{*}{16} & D16S407 & 16.7 & 0.38 & 0.30 & 0.45 & 1.54 \\
\hline & $C D$-only & & $0.93(0.019)$ & $0.76(0.031)$ & $1.04(0.014)$ & $1.63(0.049)$ \\
\hline & D16S403 & 43.0 & 0.02 & 0.16 & 0.02 & 0.11 \\
\hline & D16S3131 & 49.0 & 0.006 & 0.11 & 0.00 & -0.25 \\
\hline & D16S411 & 57.8 & 0.04 & 0.13 & 0.003 & 0.52 \\
\hline & D16S419 & 65.6 & 0.01 & 0.13 & 0.00 & 0.15 \\
\hline & D16S408 & 72.6 & 0.0002 & 0.28 & 0.09 & 0.70 \\
\hline & D16S503 & 81.8 & 0.34 & 0.37 & 0.34 & 1.17 \\
\hline
\end{tabular}

Note. Maximum two-point lod scores $\left(Z_{\max }\right)$ obtained by using the pseudomarker analysis with recessive (Rec) or dominant model (Dom) and by affected sib-pair analysis (ASP). Two-point NPL scores are also shown. $P$ values $<0.05$ are indicated in parentheses. The genetic distances (CM; centiMorgan) are based on human GeneMap (http://www.ncbi.nlm.nih.gov/genemap), except the distances for chromosome 1, which are derived from the comprehensive Marshfield genetic map. Only the significant results obtained in the subgroup analysis for disease type are presented. For the disease-specific analyses of chromosome 3 markers see Table 3.

chromosome 3p21. Our supportive linkage assignment overlaps the original linkage region on 3p21 reported by Satsangi et $a l .{ }^{2}$ So far, only the genome scan by Rioux et al. has shown multipoint lod scores over 1.5 on this region. ${ }^{17}$ Satsangi et al. observed the strongest evidence of linkage in CD families, ${ }^{2}$ while in our material the greatest evidence of linkage seems to be from the mixed families, which may reflect greater average size of the families in this group. The chromosome 3 region has also raised attention in an association study by Pokorny et al. ${ }^{30}$ who reported an increase of a specific haplotype, constructed from the alleles of the marker D3S1611 and the HNPCC (hereditary non-polyposis colon cancer) gene $M L H 1$, in IBD patients. The chromosome 3p21 region seems intriguing as it harbours, in addition to $M L H 1$, other interesting candidates genes including those encoding a cluster of chemokine receptors, and a G protein subunit $\alpha_{i 2}$ (GNAI2) the deficiency of which causes an UC-like phenotype in knockout mice. ${ }^{31}$
A striking feature of the composition of our family material was the relative excess of UC families to $\mathrm{CD}$ families. The threefold difference in prevalence rates of UC to CD, similar to the situation observed elsewhere, can not wholly explain this. Whether this means that different combinations of susceptibility genes for IBD exist in the Finns in comparison to other populations remains to be studied. Due to the nature of complex genetics and our restricted sample size regarding especially the $\mathrm{CD}$ families, failure to replicate previous findings on other chromosomes than $3 \mathrm{p} 21$, however, does not exclude the possibility that these regions would harbour Finnish IBD genes. We take our findings on the pericentromeric markers of chromosome 16 as preliminarily interesting as positive lod scores with $16 \mathrm{CD}$ families for the marker D16S407 were observed.

We selected two candidate genes showing common functional variation, one in chromosome 3 (chemokine receptor CCR5) and the other in chromosome 16 (IL4RA), 
Table 3 Disease-specific, two-point linkage analysis of IBD on chromosome 3p21

\begin{tabular}{|c|c|c|c|c|c|c|c|c|}
\hline \multirow[b]{2}{*}{ Marker } & \multirow[b]{2}{*}{ Disease type } & \multirow[b]{2}{*}{$c M$} & \multicolumn{3}{|c|}{$Z_{\max }$} & \multirow[b]{2}{*}{ NPL score } & \multicolumn{2}{|c|}{$\mathrm{P}$ value } \\
\hline & & & $\operatorname{Rec}$ & Dom & $A S P$ & & $H R R$ & $T d T$ \\
\hline \multirow[t]{4}{*}{ D3S2396 } & UC families & 46.5 & 0.00 & 0.00 & 0.00 & -0.69 & 0.50 & 0.42 \\
\hline & CD families & & 0.03 & 0.02 & 0.04 & 0.27 & 0.50 & 0.34 \\
\hline & Mixed families & & 0.30 & 0.09 & 0.19 & 0.85 & 0.50 & 0.23 \\
\hline & All & & 0.07 & 0.00 & 0.03 & 0.02 & 0.50 & 0.32 \\
\hline \multirow{4}{*}{ D3S1609 } & UC families & 49.5 & 0.00 & 0.10 & 0.06 & 0.06 & 0.50 & 0.073 \\
\hline & CD families & & 0.00 & 0.00 & 0.00 & -0.20 & 0.50 & 0.37 \\
\hline & Mixed families & & 0.69 & 0.32 & 0.66 & 0.72 & 0.50 & 0.32 \\
\hline & All & & 0.10 & 0.20 & 0.30 & 0.32 & 0.50 & 0.062 \\
\hline \multirow{4}{*}{ D3S2432 } & UC families & 51.0 & 0.92 & 0.84 & 0.92 & 1.49 & 0.50 & 0.43 \\
\hline & CD families & & 0.08 & 0.10 & 0.12 & 0.63 & 0.50 & 0.24 \\
\hline & Mixed families & & 0.78 & 0.22 & 0.46 & 0.98 & 0.10 & 0.0097 \\
\hline & All & & $\begin{array}{l}1.68 \\
(0.0027)\end{array}$ & $\begin{array}{l}1.12 \\
(0.012)\end{array}$ & $\begin{array}{l}1.48 \\
(0.0045)\end{array}$ & $\begin{array}{c}1.89 \\
(0.029)\end{array}$ & 0.50 & 0.31 \\
\hline \multirow[t]{4}{*}{ D3S1619 } & UC families & 55.4 & 0.43 & 0.16 & 0.31 & 0.82 & 0.019 & 0.030 \\
\hline & CD families & & 0.00 & 0.00 & 0.00 & -0.41 & 0.50 & 0.50 \\
\hline & Mixed families & & $\begin{array}{l}1.47 \\
(0.0047)\end{array}$ & $\begin{array}{l}1.56 \\
(0.0037)\end{array}$ & $\begin{array}{l}0.70 \\
(0.036)\end{array}$ & $\begin{array}{c}1.78 \\
(0.040)\end{array}$ & 0.50 & 0.50 \\
\hline & All & & $\begin{array}{l}0.98 \\
(0.017)\end{array}$ & 0.50 & $\begin{array}{l}0.60 \\
(0.048)\end{array}$ & 1.34 & 0.057 & 0.025 \\
\hline \multirow[t]{4}{*}{ D3S3521 } & UC families & 58.0 & 0.14 & 0.12 & 0.08 & 0.27 & 0.50 & 0.44 \\
\hline & CD families & & 0.00 & 0.00 & 0.00 & -0.24 & 0.50 & 0.25 \\
\hline & Mixed families & & 0.04 & $0.31 / 0.45^{\mathrm{a}}$ & 0.0007 & 0.53 & 0.50 & 0.40 \\
\hline & All & & 0.09 & 0.21 & 0.03 & 0.37 & 0.50 & 0.33 \\
\hline \multirow[t]{4}{*}{ D3S2304 } & UC families & 63.0 & 0.00 & 0.12 & 0.00 & -0.12 & 0.50 & 0.039 \\
\hline & CD families & & 0.00 & 0.00 & 0.00 & -0.29 & 0.50 & 0.50 \\
\hline & Mixed families & & $\begin{array}{l}0.63 / 1.04^{\mathrm{a}} \\
\left(0.044 / 0.014^{\mathrm{a}}\right)\end{array}$ & 0.06 & 0.33 & 0.76 & 0.50 & 0.037 \\
\hline & All & & 0.02 & 0.13 & 0.05 & 0.16 & 0.50 & 0.0074 \\
\hline
\end{tabular}

Note. Maximum lod scores $\left(Z_{\max }\right)$ for affected sib-pair analysis (ASP) and the pseudomarker analysis with recessive (Rec) and dominant (Dom) model. NPL scores are shown for comparison. $P$ values $<0.05$ are indicated in parentheses. In these complex families TdT is a test for linkage, and the haplotype relative risk (HRR) test measures allelic association.

a Lod score when assumption of heterogeneity gives more significance to the analysis.

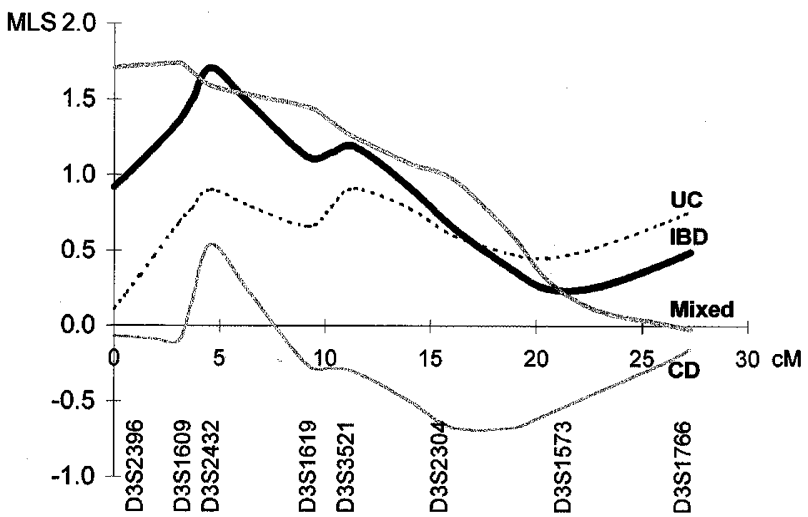

Figure 1 Multipoint non-parametric linkage analysis on chromosome 3 p21 for the total family cohort (IBD) and diseasespecific subgroups (UC, CD, and mixed families). Multipoint lod scores (MLS) were calculated by using Genehunter 2.0 version beta.

for a genetic association study. CCR5 has been shown to be abundantly expressed in colon epithelial cell lines and regulate proinflammatory chemokine production. ${ }^{32}$ A natu- rally occurring variant of CCR5 exists, where a 32-bp deletion results in synthesis of a non-functional receptor due to generation of a premature stop codon. This $\Delta 32$ variant was first identified in individuals resistant to HIV-1 infection, and was subsequently associated with reduced risk of asthma, ${ }^{22}$ possibly pointing to less liability to chronic inflammation. We did not find any significant, positive or negative, association between risk of IBD and the $\Delta 32$ variant of $C C R 5$, and there was no specific IBD group with an apparent loss of the $\Delta 32 / \Delta 32$ homozygotes (Table 4 ).

A nucleotide change A1902G of IL- 4 receptor $\alpha$-subunit, causing the replacement of glutamine (Q576) with arginine (R576), has been reported to result in increased $I L-4$ signaling and increased IgE production in vivo, and was initially suggested to be associated with atopy. ${ }^{21}$ Interestingly, a defect in responsiveness to $I L-4$ has been proposed in IBD. ${ }^{20}$ Accordingly, we hypothesised that the G1902 allele of IL4RA could be less prevalent in IBD patients than in normal controls. Although the G1902 allele frequencies were similar in the IBD group and the controls, the homozygous G1902/ G1902 genotype was slightly less common in UC patients than in controls (Table 4). Whether this is an indication that the IL4RA G1902 allele, when present in a homozygous form, 
Table 4 The frequencies of the CCR5 (432) and IL4RA (A1902G) genotypes in Finnish IBD patients and controls

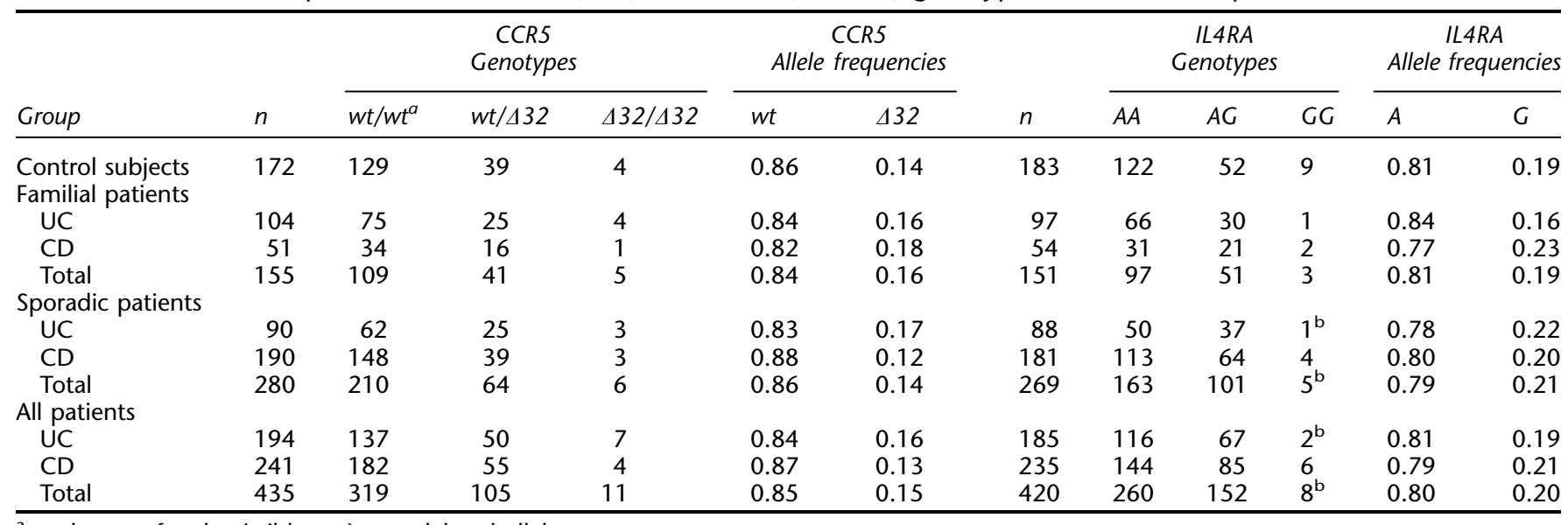

${ }^{a}$ wt denotes for the (wild-type) non-deleted allele.

${ }^{\mathrm{b}} \mathrm{P}=0.038$ for comparison of genotype distribution between controls and patients.

may exert a weak protective influence against risk of UC in specific individuals awaits additional studies using other data sets. A recent study by Olavesen et al. did not, however, reveal any significant association between risk of IBD and several intragenic single-nucleotide polymorphisms of the IL4RA gene. $^{33}$

In conclusion, our study carried out in the relatively isolated Finnish population further strengthens the linkage to 3 p21 reported in more outbred populations and thus supports the assumption that chromosome 3 contains a gene or genes conferring susceptibility to IBD.

\section{Acknowledgments}

We thank members of Finnish IBD families participating in the study. In particular, we appreciate the efforts of Dr Pekka Jauhonen from Kainuu Central Hospital, Dr Heikki Järvinen from Helsinki University Hospital, Dr Tuomo Jääskeläinen from Kemi Central Hospital, Dr Tarmo Koivisto from Lappeenranta Central Hospital, Dr Frank Laxen from Turku University Hospital, Dr Juhani Lehtola from Oulu University Hospital, Dr Pekka Pikkarainen from Tampere University Hospital, Dr Helena Tunturi-Hihnala from Seinäjoki Central Hospital, and Dr Markku Voutilainen from Jyväskylä Central Hospital, to contribute to recruitment of IBD families. We also thank Dr Tom Krusius, the Finnish Red Cross Blood Service, for providing us with the blood samples from healthy blood donors. Sirpa Stick and Tuula Soppela-Loponen are acknowledged for excellent laboratory assistance, and Paula Leinonen for assisting in collection of patients and hospital records. The study was supported by the Medical Research Funds of the Helsinki University Central Hospital and the Council of Health Sciences of Finnish Academy. Dr Joseph Terwilliger has a HitchingsElion fellowship from the Burroughs-Wellcome Fund. SIMSIBS is a PASCAL program that is available from $\mathrm{Dr}$ Terwilliger.

\section{References}

1 Hugot JP, Laurent-Puig P, Gower-Rousseau C et al: Mapping of a susceptibility locus for Crohn's disease on chromosome 16. Nature 1996; 379: 821-823.
2 Satsangi J, Parkes M, Louis E et al: Two stage genome-wide search in inflammatory bowel disease provides evidence for susceptibility loci on chromosomes 3, 7 and 12. Nat Genet 1996; 14: 199-202.

3 Ohmen JD, Yang HY, Yamamoto KK et al: Susceptibility locus for inflammatory bowel disease on chromosome 16 has a role in Crohn's disease, but not in ulcerative colitis. Hum Mol Genet 1996; 5: 1679-1683.

4 Brant SR, Fu Y, Fields CT et al: American families with Crohn's disease have strong evidence for linkage to chromosome 16 but not chromosome 12. Gastroenterology 1998; 115: 1056-1061.

5 Cavanaugh JA, Callen DF, Wilson SR et al: Analysis of Australian Crohn's disease pedigrees refines the localization for susceptibility to inflammatory bowel disease on chromosome 16. Ann Hum Genet 1998; 62: 291-298.

6 Cho JH, Nicolae DL, Gold LH et al: Identification of novel susceptibility loci for inflammatory bowel disease on chromosomes $1 \mathrm{p}, 3 \mathrm{q}$, and $4 \mathrm{q}$ : evidence for epistasis between $1 \mathrm{p}$ and IBD1. Proc Natl Acad Sci USA 1998; 95: 7502 - 7507.

7 Curran ME, Lau KF, Hampe J et al: Genetic analysis of inflammatory bowel disease in a large European cohort supports linkage to chromosomes 12 and 16. Gastroenterology 1998; 115: $1066-1071$

8 Mirza MM, Lee J, Teare D et al: Evidence of linkage of the inflammatory bowel disease susceptibility locus on chromosome 16 (IBD1) to ulcerative colitis. J Med Genet 1998; 35: 218 221.

9 Annese V, Latiano A, Bovio P et al: Genetic analysis in Italian families with inflammatory bowel disease supports linkage to the IBD1 locus - a GISC study. Eur J Hum Genet 1999; 7: 567 573.

10 Hampe J, Schreiber S, Shaw SH et al: A genomewide analysis provides evidence for novel linkages in inflammatory bowel disease in a large European cohort. Am J Hum Genet 1999; 64: $808-816$.

11 Ma Y, Ohmen JD, Li Z et al: A genome-wide search identifies potential new susceptibility loci for Crohn's disease. Inflamm Bowel Dis 1999; 5: 271-278.

12 Duerr RH, Barmada MM, Zhang L, Pfutzer R, Weeks DE: Highdensity genome scan in Crohn disease shows confirmed linkage to chromosome 14q11-12. Am J Hum Genet 2000; 66: 18571862 .

13 Hugot JP, Zouali H, Lesage S, Thomas G: Etiology of the inflammatory bowel diseases. Int J Colorectal Dis 1999; 14: 2-9. 
14 Duerr RH, Barmada MM, Zhang L et al: Linkage and association between inflammatory bowel disease and a locus on chromosome 12. Am J Hum Genet 1998; 63: 95 - 100.

15 Hampe J, Shaw SH, Saiz R et al: Linkage of inflammatory bowel disease to human chromosome 6p. Am J Hum Genet 1999; 65: $1647-1655$

16 Yang H, Plevy SE, Taylor K et al: Linkage of Crohn's disease to the major histocompatibility complex region is detected by multiple non-parametric analyses. Gut 1999; 44: 519-526.

17 Rioux JD, Silverberg MS, Daly MJ et al: Genomewide search in Canadian families with inflammatory bowel disease reveals two novel susceptibility loci. Am J Hum Genet 2000; 66: 1863 - 1870.

18 Cho JH, Nicolae DL, Ramos $\mathrm{R}$ et al: Linkage and linkage disequilibrium in chromosome band 1p36 in American Chaldeans with inflammatory bowel disease. Hum Mol Genet 2000; 9: $1425-1432$

19 Karvonen A-L, Tunturi-Hihnala H, Krekelä I, Björknäs H, Toivanen E: Epidemiology of inflammatory bowel diseases in the region of Tampere University Hospital. Scand J Gastroenterol 1993; 28 (Suppl. 197): 77.

20 Schreiber S, Heinig T, Panzer U et al: Impaired response of activated mononuclear phagocytes to interleukin 4 in inflammatory bowel disease. Gastroenterology 1995; 108: 21 - 33 .

21 Hershey GK, Friedrich MF, Esswein LA, Thomas ML, Chatila TA: The association of atopy with a gain-of-function mutation in the alpha subunit of the interleukin-4 receptor. $N$ Engl J Med 1997; 337: 1720-1725.

22 Hall IP, Wheatley A, Christie G, McDougall C, Hubbard R, Helms PJ: Association of CCR5 delta32 with reduced risk of asthma. Lancet 1999; 354: $1264-1265$.

23 Noguchi E, Shibasaki M, Arinami T et al: Lack of association of atopy/asthma and the interleukin-4 receptor alpha gene in Japanese. Clin Exp Allergy 1999; 29: 228-233.

24 Göring HH, Terwilliger JD: Linkage analysis in the presence of errors IV: Joint pseudomarker analysis of linkage and/or linkage disequilibrium on a mixture of pedigrees and singletons when the mode of inheritance cannot be accurately specified. Am J Hum Genet 2000; 66: 1310-1327.
25 Lathrop GM, Lalouel JM, Julier C, Ott J: Strategies for multilocus linkage analysis in humans. Proc Natl Acad Sci USA 1984; 81: 3443 - 3446.

26 Cottingham Jr, RW, Idury RM, Schaffer AA: Faster sequential genetic linkage computations. Am J Hum Genet 1993; 53: 252 263.

27 Kruglyak L, Daly MJ, Reeve-Daly MP, Lander ES: Parametric and nonparametric linkage analysis: a unified multipoint approach. Am J Hum Genet 1996; 58: 1347 - 1363.

28 Terwilliger JD: A powerful likelihood method for the analysis of linkage disequilibrium between trait loci and one or more polymorphic marker loci. Am J Hum Genet 1995; 56: 777-787.

29 Terwilliger JD, Shannon WD, Lathrop GM et al: True and false positive peaks in genomewide scans: applications of lengthbiased sampling to linkage mapping. Am J Hum Genet 1997; 61: $430-438$

30 Pokorny RM, Hofmeister A, Galandiuk S, Dietz AB, Cohen ND, Neibergs HL: Crohn's disease and ulcerative colitis are associated with the DNA repair gene MLH1. Ann Surg 1997; 225: $718-723$.

31 Rudolph U, Finegold MJ, Rich SS et al: Ulcerative colitis and adenocarcinoma of the colon in $\mathrm{G}$ alpha i2-deficient mice. Nat Genet 1995; 10: $143-150$.

32 Dwinell MB, Eckmann L, Leopard JD, Varki NM, Kagnoff MF: Chemokine receptor expression by human intestinal epithelial cells. Gastroenterology 1999; 117: 359-367.

33 Olavesen M, Hampe J, Mirza MM et al: Analysis of singlenucleotide polymorphisms in the interleukin-4 receptor gene for association with inflammatory bowel disease. Immunogenetics 2000; 51: $1-7$. 